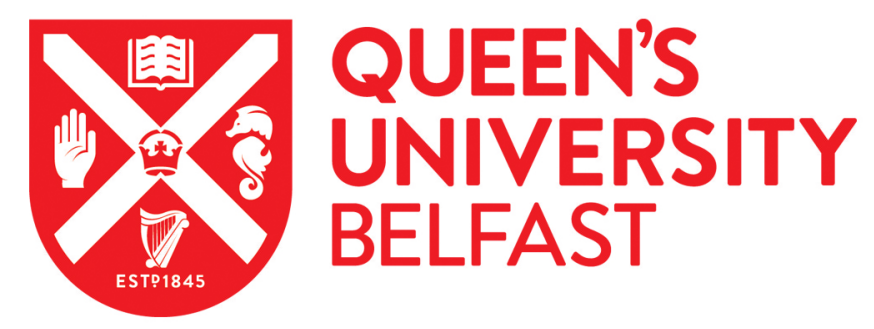

\title{
Beyond the irony of intergroup contact: The effects of contact and threat on political participation and support for political violence in Northern Ireland
}

McKeown, S., \& Taylor, L. K. (2017). Beyond the irony of intergroup contact: The effects of contact and threat on political participation and support for political violence in Northern Ireland. Group Dynamics: Theory, Research, and Practice, 21(4), 234-244. https://doi.org/10.1037/gdn0000074

Published in:

Group Dynamics: Theory, Research, and Practice

Document Version:

Peer reviewed version

Queen's University Belfast - Research Portal:

Link to publication record in Queen's University Belfast Research Portal

Publisher rights

(C) 2016 American Psychological Association.

This work is made available online in accordance with the publisher's policies. Please refer to any applicable terms of use of the publisher

\section{General rights}

Copyright for the publications made accessible via the Queen's University Belfast Research Portal is retained by the author(s) and / or other copyright owners and it is a condition of accessing these publications that users recognise and abide by the legal requirements associated with these rights.

Take down policy

The Research Portal is Queen's institutional repository that provides access to Queen's research output. Every effort has been made to ensure that content in the Research Portal does not infringe any person's rights, or applicable UK laws. If you discover content in the

Research Portal that you believe breaches copyright or violates any law, please contact openaccess@qub.ac.uk. 
Beyond the irony of intergroup contact: The effects of contact and threat on political participation and support for political violence in Northern Ireland

\begin{abstract}
Research suggests that intergroup contact can ironically lead to a reduction in commitment to social change and that threat can play an important role in this process. In post- agreement societies, however, characterised more so by symbolic rather than material conflict, the role that intergroup contact and threat play in social action may be particularly complex. This paper examines intergroup contact, intergroup threat, support for political violence, and political participation, among a student sample $(n=152)$ of Protestants and Catholics in Northern Ireland. Results show that contact is associated with lower symbolic and realistic threat for both groups, and to lower levels of support for political violence but not to political participation. Symbolic threat mediated the association between contact and support for political violence and between contact and political participation for the Protestant majority group only. This suggests that contact may have a positive effect upon group relations but that this is dependent upon status and the social-political context.
\end{abstract}

Key words

Political participation; Collective action; Intergroup contact; Threat; Northern Ireland. 
Beyond the irony of intergroup contact: The effects of contact and threat on political participation and support for political violence in Northern Ireland

Research on intergroup contact has demonstrated an 'ironic effect' of contact for minority groups, such that it can reduce prejudice but at the same time reduce collective action tendencies (Dixon, Levine, Reicher \& Durrheim, 2012; Saguy, Tausch, Dovidio \& Pratto, 2009). Further, whilst positive contact is associated with increased support for social change policies amongst majority group members (Dixon et al., 2012), this may not translate into practice (Saguy, Tropp \& Hawi, 2013). This ironic effect of contact is clearly problematic in situations of pronounced structural inequalities which perpetuate division and conflict. And further, is often associated with threat perceptions. However, the ironic effects of contact through threat are less clear in situations where inequalities have been significantly reduced and peacebuilding becomes the primary goal. The research presented here aimed to examine the intricacies of the relationship between contact, threat and different forms of collective action, namely participation in political activities and support for political violence in the post-conflict setting of Northern Ireland. It is argued here that whilst contact can reduce tendencies towards collective action, the effects may depend on threat perceptions, the type of action being measured, group status and the specific context of intergroup interactions.

\section{Intergroup Contact, Group Status and Collective Action}

Described as one of the most successful theories in social psychology (Dovidio, Gaertner \& Kawakami, 2003), in its simplest form, the contact hypothesis states that bringing groups together under favourable conditions can help to reduce intergroup 
prejudice and in turn foster positive community relations (Allport, 1954). The contact hypothesis has been supported in a large range of studies which have illustrated a modest but reliable relationship between contact and prejudice reduction (Pettigrew \& Tropp, 2006).

However, these effects vary by group status. Tropp and Pettigrew (2005) reported that contact works better to reduce prejudice among majority members. Additionally, whilst contact can reduce majority group members' negative and aggressive action tendencies towards minority groups (Schmid, Hewstone, Kupper, Zick \& Tausch, 2014), evidence is emerging that improving group attitudes through contact can have negative consequences for minority group members as it weakens their commitment to social change and thereby perpetuates their disadvantage (Dixon et al., 2012; Saguy et al., 2009).

This relationship is further complicated by the range of collective actions on which contact can exert an effect. As Wright (2009) points out, it is vital to distinguish the psychological mechanisms underpinning the link between contact and different forms of collective action, for example, what leads to attending a protest, compared to throwing a petrol bomb, as these will have very different consequences for intergroup relations. Evidence for this comes from Becker, Tausch, Spears and Christ (2011), who found that participation in radical action was associated with disidentification from the ingroup; however, this was not the case for moderate action. The present study, therefore, focuses on (1) political participation, and (2) support for political violence as different forms of collective action.

This differentiation facilitates an understanding of the conditions under which individuals are more likely to engage in different varieties of collective action. For example, Schmid et al. (2014) examined aggressive action tendencies of majority 
group members towards immigrants across a number of European countries and found that contact was associated with a reduction in realistic threat and thereby a reduction in aggressive action tendencies. In a second study, which focused on relations between Protestants and Catholics in Northern Ireland, they found support for the longitudinal effects of contact in predicting a reduction in aggressive collective action at Time 2, again mediated through a reduction in realistic threat. In other words, the role of contact in reducing the level of perceived intergroup threat is central in predicting the form and level of subsequent aggressive action. This study, however, focused more closely on aggressive action rather than different forms of collective action tendencies.

Whilst there is some evidence that the consequences of different forms of collective action differently affect intergroup relations (Becker et al., 2011), there is little evidence on how this may be associated with group status in a real life conflict setting which has transitioned towards peace. This is an important limitation because minority and majority groups are likely to perceive and respond to threat differently. For example, previous research has suggested that high status groups are more likely to respond to threat with more force than low status groups (Stephan \& Mealy, 2011). Moreover, both groups' responses are likely to be shaped by the prior history and the current political context of intergroup interactions.

Bringing these findings together, it is argued that a consideration of the social context and of group status seems vital in any understanding of the relationship between intergroup contact, threat and different forms of collective action. This is particularly important in post-conflict settings where some level of political violence may persist but political engagement is still vital to maintain a viable social order. 
The present study aims to examine these intricate processes in a real life conflict setting where group differences are complex and dynamic: Northern Ireland.

\section{The Present Study}

Northern Ireland is an ethno-politically divided society in which historically the Protestant/British/Unionists were numerically, politically and economically superior to the Catholic/Irish/Nationalists (Cairns \& Darby, 1998). In recent decades, the conflict is characterised by symbolic rather than material conflict, with group differences at the core. Group differences in this context are not physiognomic, yet individuals can categorise identity through explicit as well as subtle symbolic indicators. For example, flags, symbols, paintings, words, and clothing signify group membership identity and are associated with protests and political participation, as well as a means to mark territory.

The population of Northern Ireland currently stands at 1.811 million, of which $45 \%$ of the resident population are Catholic and $48 \%$ are Protestant. This is a marked difference from the 1991 census, which was taken before the Good Friday/Belfast Peace Agreement, in which $42 \%$ self-identified as Protestant and 58\% identified as Catholic. Whilst the Northern Ireland demographic is changing, historically Catholics are viewed as the economically and numerically disadvantaged group compared to Protestants and still remain disadvantaged in today's Northern Ireland. For example, the 2014 Peace Monitoring Report shows that "Catholics still experience more economic and social disadvantage than Protestants" (Nolan, 2014, p.13) and that they are more likely to be unemployed and in poor health, compared to Protestants. 
Indeed, the recent conflict in Northern Ireland, known as the "Troubles", emerged from disputes in the late 1960's over economic and political inequalities but escalated into a violent conflict over the constitutional state of Northern Ireland (Cairns \& Darby, 1998). In 1998, the Good Friday/ Belfast Agreement was signed which locked both groups into a 'consociational' power-sharing arrangement and institutionalized policies of intergroup equality and good relations. However, group relations remain fraught in Northern Ireland; a low level of political violence persists and the political agreement is unstable. As a result, the role of contact in promoting better intergroup relations, while maintaining the political engagement of both groups, has arguably never been more important.

A substantial body of research has demonstrated a positive effect of contact on intergroup attitudes in this context (c.f. Cairns, Kenworthy, Campbell, \& Hewstone, 2006; Hewstone et al. 2004; McKeown, Cairns, Stringer \& Rae, 2012; Paolini, Hewstone, Cairns, \& Voci, 2004) but as yet little attention has been paid to its potentially ironic impact on different types of collective action through symbolic and realistic threat.

\section{Aim and Hypotheses}

The aim of the present study is to understand the effects of intergroup contact on political participation and support for political violence, through intergroup threat (symbolic and realistic) and how this relationship may differ depending on group status. It addresses an important gap in the literature by measuring different forms of action (Wright et al., 2009): mild (political participation) and aggressive (support for political violence) in a real life context; in this case, relations between Protestants and Catholics in Northern Ireland. 
Importantly, this research draws upon previous studies which have demonstrated that intergroup contact can reduce aggressive collection action tendencies for both majority and minority group members through reductions in threat (Schmid et al., 2014). The consideration of threat is particularly important in Northern Ireland due to the symbolic and material nature conflict. Whilst Schmid et al. found that only realistic threat can reduce aggressive action tendencies, the present study considered both realistic and symbolic threat due to the nature of the Northern Irish conflict in which both threats remain important. Based on this theoretical and empirical literature and the complexity of intergroup relations in the context of Northern Ireland, within the context of the overall conceptual model, it was hypothesised that:

1. Intergroup contact will be associated with lower levels of political participation, particularly for the Catholic minority group;

2. Intergroup contact will be associated with lower levels of support for political violence, particularly for the Catholic minority group;

3. Intergroup contact will be associated with lower levels of political participation through lower levels of symbolic and realistic threat and that these effects will be moderated by group status; and,

4. Intergroup contact will be associated with lower levels of support for political violence through lower levels of symbolic and realistic threat and that these effects will be moderated by group status.

The overall conceptual model for Hypotheses 1 and 3 is presented in Figure 1 and for Hypotheses 2 and 4 are presented in Figure 2. 


\section{Method}

\section{Sample}

Student participants $(n=152)$ were recruited from a university in Northern Ireland. Participants were approached in social areas of the university and volunteered to complete a paper based survey; no compensation was given for their participation. The sample included 22 males and 130 females with a mean age of 22.31. Of these, 85 self-identified as Catholic and 67 as Protestant.

\section{Measures}

Demographics. Participants were asked for demographic information such as gender, age, country of birth and religious affiliation as well as the following:

Political participation. Participants rated on a 5-point scale (never to very often), how often they "participated in political activities" and how often they "display symbols associated with your community". These two items were collapsed to measure political participation (Cronbach $\alpha=.66$ ).

Support for political violence. Participants rated on a 5-point scale (strongly disagree to strongly agree), to what extent they agreed with three statements including: "In general I understand my group's reasons for the use of violence throughout the conflict", "In general, I have sympathy for my groups reasons for resorting to violent means throughout the conflict", and a final reversed coded item "In general, I do not support my groups decisions to use violence throughout the conflict" $(\alpha=.73)$.

Threat: Building upon previous research both symbolic threat (associated with cultural/identity threat) and realistic threat (associated with resources) were measured in this study. Participants were asked to rate to what extent they agreed or disagreed with each statement on a 5-point Likert scale (strongly disagree to strongly 
agree). Adapted from Stephan et al. (2002) symbolic threat was measured by four items e.g. "Our way of life would be better if there were fewer members of the other community living here" $(\alpha=.73)$, and realistic threat was measured with four items e.g. "The other community has more economic power in Northern Ireland than they should" $(\alpha=.75)$.

Intergroup contact. Adapted from Voci and Hewstone, (2003), quality of contact was measured by asking participants to rate on a 7-point Likert scale to what extent they find contact with the other community "pleasant or unpleasant" and "rather positive or negative" $(\alpha=.90)$. Quantity of contact, also adapted from Voci and Hewstone (2003), was measured by asking participants to rate on a 5-point Likert scale ranging from "none at all" to "a great deal", how much contact they have with people from the other community "at meetings and events", "just chatting to people" and "over all social situations" $(\alpha=.83)$. Following Voci and Hewstone (2003), a single measure of contact was calculated by multiplying together quality and quantity of contact, with a high score indicating high frequency positive contact.

\section{Results}

\section{Confirmatory Factor Analysis}

A confirmatory factor analyses (CFA) using AMOS was conducted to examine a two-factor solution for symbolic and realistic threat. The CFA revealed that a two factor model had good fit for the data $\left(\chi^{2}=22.670, \mathrm{df}=19, p=.252, \mathrm{CFI} .96, \mathrm{RMSEA}=.05\right)$ whilst the one factor solution had poor fit to the data $\left(\chi^{2}=48.575\right.$, $\mathrm{df}=20, p<.001$, CFI .92, RMSEA $=.097)$. The chi-square difference test confirmed that two-factor solution was a better fit to the data $(\Delta \delta, \operatorname{df}(1)=25.91, p<.05)$ and thus, a two factor solution was retained. 


\section{Moderated Mediation Analyses}

To examine the relations among contact, threat, support for political violence and political participation, the direct and indirect effects were examined using the PROCESS model for SPSS. Two separate moderated mediation models (Model 59, Hayes, 2013) were tested with contact as the predictor variable (X), symbolic and realistic threat as the mediator variables $(\mathrm{M})$, and support for political violence and political participation as outcome variables (Y), respectively. Group status (majority or minority) was the moderator (W) in both models. Indirect effects were tested using bootstrapped confidence intervals with 50,000 samples. A significant indirect effect is observed when the confidence intervals exclude zero. Results are presented for each hypothesis with direct and indirect effects presented in Tables. See Table 1 for correlations and descriptive statistics.

\section{INSERT TABLE 1 ABOUT HERE}

\section{Hypothesis 1: Contact and political participation}

It was hypothesised that, within the overall model, intergroup contact would be associated with lower levels of political participation, particularly for the Catholic minority. Results indicate that in contrast to the hypothesis, there was no significant direct relation between contact and political participation, between group status and political participation, and no contact*group status interaction effect (Table 2c).

\section{INSERT TABLES 2abc ABOUT HERE}

\section{Hypothesis 2: Contact and support for political violence}

Within the overall model, it was hypothesised that intergroup contact would be associated with lower levels of support for political violence, particularly for the Catholic minority. In partial support of this hypothesis, contact was found to be related to lower levels of support for political violence. There was no direct effect of 
group status on political violence. Adopting a significance threshold of $p<.05$, there was no contact*group status interaction effect (Table 3c). However, it is worth noting that this effect was $p=.05$, which may be interpreted as significant at the trend level, and suggests that the link from contact to support for political violence is weaker for Protestants than for Catholics (See Figure 3). Amongst those who report less contact, Protestants score higher on support for political violence relative to Catholics.

\section{INSERT TABLES 3abc ABOUT HERE \\ INSERT FIGURE 3 ABOUT HERE}

\section{Hypothesis 3: Contact-threat-political participation}

It was hypothesised that group status would moderate the mediation effects from intergroup contact on political participation through lower levels of symbolic and realistic threat. Overall, the moderated mediation model explained $13 \%$ of the variance in political participation $\left(R^{2}=.13, F(7,144)=3.18, p=.004\right.$; Tables $2 \mathrm{a}, 2 \mathrm{~b}$, and $2 \mathrm{c}$ ). The paths from intergroup contact to symbolic threat and to realistic threat were negative; this indicates that contact is related to lower levels of both forms of threat. By contrast, the path from symbolic threat to political participation was positive; this suggests that symbolic threat is associated with higher political participation. There was no significant link, however, from realistic threat to political participation, which suggests that realistic threat is not related to political participation.

Tests for interaction effects demonstrate that there was only one significant interaction effect: group status moderated the path from symbolic threat to political participation. The negative sign of this interaction effect implies that the relation between symbolic threat and political participation is weaker for the majority 
Protestant sample compared to the minority Catholic sample. Group status did not significantly affect the strength of the relations between any of the other paths.

Tests for moderated mediation were conducted (Table 4). In contrast to the hypothesis, there was evidence for overall moderated mediation through symbolic threat $(.0251, \mathrm{se}=.0097,95 \%$ CI $[.0078, .0463])$ but not realistic threat $(.0057, \mathrm{se}=$ $.0069,95 \%$ CI [-. 0065, .0209] ). This provides evidence that the indirect effect of contact on political participation, through symbolic threat, is dependent on group status. More specifically, this indirect effect was significant for the Protestant majority group (-. 0263, se $=.0086,95 \%$ CI $[-.0462,-.0118])$, but not for the Catholic minority group (-. 0012, se $=.0045,95 \%$ CI $[-.0133, .0056])$.

\section{INSERT TABLE 4 ABOUT HERE}

\section{Hypothesis 4: Contact-threat-support for political violence}

It was hypothesised that group status would moderate the mediation effects from intergroup contact on support for political violence through lower levels of symbolic and realistic threat. Overall, the moderated mediation model explained $17 \%$ of the variance in political participation $\left(R^{2}=.17, F(7,144)=4.247, p<.001\right.$; Tables 3a, $3 \mathrm{~b}$, and $3 \mathrm{c})$. There was no significant link from symbolic threat to support for political violence or from realistic threat to support for political violence.

There were no significant interactions of group status on any of the paths tested. In addition, tests of moderated mediation found that neither the overall indirect effect of symbolic threat $(.0144, \mathrm{se}=.0116,95 \%$ CI $[-.0064, .0389])$ nor realistic threat $($. $0057, \mathrm{se}=.0069,95 \% \mathrm{CI}[-.0065, .0209]$; Table 5) from contact to support for political violence were dependent on group status. However, examining the specific indirect paths for moderated mediation by group found an indirect effect between contact and support for violence through symbolic threat for the Protestant majority 
group (-. 0223, se $=.0096,95 \%$ CI $[-.0461,-.0073])$, but not for the Catholic minority $(-.0079, \mathrm{se}=.0064,95 \%$ CI $[-.0235, .0023])$. Thus, symbolic threat mediated the impact of contact on support for violence among Protestants, but not Catholics.

\section{INSERT TABLE 5 ABOUT HERE}

\section{Discussion}

Evidence suggests that contact can reduce collective action tendencies amongst majority and minority groups and that threat can influence this relationship. This paper set out to investigate the effects of contact and threat upon different forms of collective action for majority and minority group members in a post-conflict society, Northern Ireland. It was hypothesised that contact would be associated with lower levels of political participation and lower levels of support for violence, particularly for the Catholic minority group. It was further hypothesised that the relationship between contact and both forms of collective action would be mediated by threat. In support of previous research, contact was found to be associated with lower levels of symbolic and realistic threat. When all variables were included in the model (Tables $2 \mathrm{c}$ and $3 \mathrm{c}$ ), contact was also found to be associated with lower levels of support for political violence but not with political participation. Moderated mediation analysis demonstrated that contact was related to lower levels of symbolic threat perception and subsequently lower levels of both support for political violence and political participation, but only for the Protestant majority group. For the Catholic minority group, there were no indirect effects of contact on political participation or support for political violence through either forms of threat. 
Taken together these are important because they demonstrate, at least in the case of Northern Ireland, that (1) contact is associated with lower levels of the most detrimental form of collective action, i.e. support for political violence, and (2) that contact does not reduce the more constructive form of political activities essential in sustaining a political arrangement and promoting social equality. The indirect effect of symbolic threat in reducing both forms of participation for the Protestant majority group is also promising for promoting social equality in Northern Ireland. This is because higher levels of political participation amongst Protestants may in fact serve to maintain the social hierarchy and thereby social inequality. Therefore, these results are in line with previous research (e.g. Dixon et al., 2012; Saguy et al., 2013) which demonstrates that contact is associated with increased support for social equality amongst majority group members and reduced tendency towards violent actions (Schmid et al., 2014). The trend-level group status*contact interaction effect suggests that Protestants who report less frequent and lower quality contact show more support for political violence relative to Catholics. Further, amongst those who report more and better quality contact, Protestants are less likely to support political violence than Catholics. Given that this interaction effect is bordering the significance threshold, it should be interpreted with caution and replicated in future research. Nevertheless, it does offer some indication that, at least amongst this sample and for this particular outcome, contact works in different ways for the majority and minority group relative to one another.

These findings may be due to a number of characteristics present in (but not unique to) Northern Ireland as a post-conflict society. In Northern Ireland, equality is institutionalised in the power-sharing arrangements. Insofar as there is a perceived difference in status between the groups, political participation can be perceived as 
geared towards improving the status of a historically disadvantaged minority. For this group then, participation has an automatic pay-off, independent of relations with the other side and therefore could be argued to be associated with promoting social equality. However, within the zero-sum game of Northern Ireland politics, Unionist politicians often report feeling sense of constant loss and threat to their previously dominant status. Thus, political participation and the assertion of political voice are typical responses to perceived threat, and for Protestants, may be associated with maintaining the current social hierarchy. Indeed, over the past number of years the disengagement of more moderate Unionists has been noted along with an increased association of local political engagement with violence (where local Loyalist activists publically protest a political arrangement that they feel does not express or represent their interests). In other words, while both sides may feel more or less threat, this will lead to very different outcomes according to how they articulate with the political system. Consequently, contact through threat may reduce support for violence and political disengagement only for the group for whom threat fuels protest. The observed indirect effect of contact on support for violence/ political participation through symbolic threat offers further support for the importance of symbolic threats over realistic threats in Northern Ireland, at least for the majority group. This may be a function of the current status quo in Northern Ireland where resource threat has been substantially reduced and relations between groups are now heavily characterised by symbolic differences. It may also be related to the majority groups perceived position in society.

Whilst these findings are based on a very particular context, they could be relevant to other contexts in which group relations are based on symbolic divisions and where relative peace exists. For example, previous research in South Africa has shown that 
the contact-collective action relationship can be different depending on the hierarchical nature of intergroup relations in a given society, such that for interminority relations contact can promote collective action tendencies (Dixon et al., 2015). As such, understanding the nature of collective action for whom and in which context is an important direction for future research.

\section{Limitations and Directions for Future research}

Whilst this research aimed to embed an understanding of the ironic effects of contact through threat within a particular social and historical context, there are some limitations to this approach that should be considered in future research. First, the sample was drawn from a population of well-educated university students who arguably do not represent the wide range of views and perceptions of the Northern Irish context. Therefore, the results may not generalise to Northern Irish society more broadly. This may be why, for example, the mean scores for political participation are quite low amongst both groups. Second, the data are correlational and cross-sectional; therefore, causation cannot be determined and there are methodological limitations for determining the direction of effects in cross-sectional mediation (Maxwell \& Cole, 2007). Third, the measure of political participation relies on two single items which may not fully capture the nature of political participation in Northern Irish society. This measure, therefore, could be adapted to include different levels of political participation and perhaps differentiate between aggressive (e.g., protesting or use of violence during protests) and benign (e.g., signing a petition) forms of political participation. Fourth, the focus here has been on positive contact; therefore, the effects of negative contact cannot be determined. Future research should aim to consider both forms of contact as emerging evidence demonstrates that negative 
contact can also be a predictor of collective action tendencies (Reimer et al., in press). Fifth, the research presented here focuses on a very specific context of majority and minority relations and therefore, future research is needed to examine whether these findings hold for other post-agreement societies. Despite these limitations, this research adds an important contribution to the debate on the ironic effects of contact by illustrating the complex and asymmetrical effects of contact as a peace-building tool in a society working through the complexities of associations with threat in a society experiencing a post-accord phase. And, whilst the research has taken place in a specific conflict setting, studying collective actions in context is vital for teasing apart violent and non-violent behaviours and associated consequences and for understanding differences between minority and majority groups in conflict and postconflict settings. 


\section{References}

Allport, G. A. (1954). The Nature of Prejudice. Reading, MA: Addison- Wesley.

Becker, J. C., Tausch, N., Spears, R., \& Christ, O. (2011). Committed dis (s) idents: Participation in radical collective action fosters disidentification with the broader in-group but enhances political identification. Personality and Social Psychology Bulletin, 37, 1104-1116.

Cairns, E., \& Darby, J. (1998). The conflict in Northern Ireland: Causes, consequences and controls. American Psychologist, 53, 754-760. Doi: 10.1037/0003-066X.53.7.754.

Cairns, E., Kenworthy, J., Campbell, A., \& Hewstone, M., (2006). The role of ingroup identification, religious group membership, and intergroup conflict in moderating in-group and out-group affect. British Journal of Social Psychology, 45, 701-716. doi: 10.1348/014466605X69850.

Dixon, J., Durrheim, K., Thomae, M., Tredoux, C., Kerr, P., \& Quayle, M. (2015). Divide and rule, unite and resist: Contact, collective action and policy attitudes among historically disadvantaged groups. Journal of Social Issues,71, 576596. 
Dixon, J., Levine, M., Reicher, S., \& Durrheim, K. (2012). Beyond prejudice: Are negative evaluations the problem and is getting us to like one another more the solution?. Behavioral and Brain Sciences, 35, 411-425.

Dovidio, J.F., Gaertner, S.L., \& Kawakami, K. (2003). Intergroup Contact: The Past, Present, and the Future. Group Processes \& Intergroup Relations, 6, 5-21. doi: $10.1177 / 1368430203006001009$.

Hayes, A. F. (2013). Introduction to mediation, moderation, and conditional process analysis: A regression-based approach. New York: The Guilford Press.

Hewstone, M., Cairns, E., Voci, A., McLernon, F., Niens, U., \& Noor, M. (2004). Intergroup forgiveness and guilt in Northern Ireland: Social psychological dimensions of "the Troubles." In N. R. Branscombe \& B. Doosje (Eds.), Collective guilt: International perspectives (pp. 193-215). New York: Cambridge University Press.

Maxwell, S. \& Cole, D. (2007). Bias in Cross-Sectional Analyses of Longitudinal Mediation. Psychological Methods, 12(1), 23-44. Doi: 10.1037/1082989X.12.1.23

McKeown, S., Cairns, E., Stringer, M., \& Rae, G. (2012). Micro-ecological behavior and intergroup contact. The Journal of social psychology, 152, 340-358. Doi: $10.1080 / 00224545.2011 .614647$.

Nolan, P. (2014). Northern Ireland peace monitoring report. Community Relations Council: Northern Ireland. Retrieved September 2016: http://www.community-relations.org.uk/wpcontent/uploads/2013/11/Peace-Monitoring-Report-2014.pdf

Paolini, S., Hewstone, M., Cairns, E., \& Voci, A. (2004). Effects of direct and indirect cross-group friendships on judgements of Catholic and Protestants in Northern 
Ireland: The mediating role of an anxiety-reduction mechanism. Personality and Social Psychology Bulletin, 30, 770-786. doi:

$10.1177 / 0146167203262848$

Pettigrew, T.F., \& Tropp, L.R. (2006). A meta-analytic test of intergroup contact theory. Journal of Personality and Social Psychology, 90, 751-783. Doi: 10.1037/0022-3514.90.5.751.

Reimer, N. K., Becker, J. C., Benz, A., Christ, O., Dhont, K., Klocke, U., ... Hewstone, M. (in press). Intergroup contact and social change: Implications of negative and positive contact for collective action in advantaged and disadvantaged groups. Personality and Social Psychology Bulletin.

Saguy, T., Tausch. N., Dovidio, J.F., \& Pratto, F. (2009). The Irony of Harmony: Intergroup Contact Can Produce False Expectations for Equality. Psychological Science, 20, 114. doi: 10.1111/j.1467-9280.2008.02261.x

Saguy, T., Tropp, L. R. , \& Hawi, D. R. (2013). The role of group power in intergroup contact. In G. Hodson \& M. Hewstone (Eds.), Advances in intergroup contact (pp. 113-132). New York: Psychology Press.

Schmid, K., Hewstone, M., Kupper, B., Zick, A., \& Tausch, N. (2014). Reducing Aggressive Intergroup Action Tendencies: Effects of Intergroup Contact Via Perceived Intergroup Threat. Aggressive Behaviour, 40, 250-262.

Stephan, W. G., Boniecki, K. A., Ybarra, O., Bettencourt, A., Ervin, K. S., Jackson, L. A., McNatt, P. S., \& Renfro, C. L. (2002). The role of threats in the racial attitudes of Blacks and Whites. Personality and Social Psychology Bulletin, 28, 1242-1254. Doi: 10.1177/01461672022812009.

Stephan, W.G. \& Mealy, M.D. (2011). Intergroup threat theory. The Encyclopedia of Peace Psychology. doi: 10.1002/9780470672532.wbepp139 
Stephan, W. G \& Stephan, C. (1985). Intergroup anxiety. Journal of Social Issues, 41, 157-176. doi: 10.1111/j.1540-4560.1985.tb01134.x.

Tropp, L.R., \& Pettigrew, T.F. (2005). Relationships Between Intergroup Contact and Prejudice Among Minority and Majority Status Groups. Psychological Science, 16, 951. doi: 10.1111/j.1467-9280.2005.01643.x

Voci, A., \& Hewstone, M. (2003). Intergroup Contact and Prejudice Toward Immigrants in Italy: The Mediational Role of Anxiety and the Moderational Role of Group Salience. Group Processes and Intergroup relations, 6, 37-54. doi: $10.1177 / 1368430203006001011$

Wright, S. C. (2009). The next generation of collective action research. Journal of Social Issues, 65, 859-879. Doi: 10.1111/j.1540-4560.2009.01628.x 